\title{
Treatment profile and complications associated with cryotherapy for localized prostate cancer: A population-based study
}

\author{
CB Roberts ${ }^{1}$, TL Jang ${ }^{2,3,4}$, Yu-Hsuan Shao ${ }^{2}$, S Kabadi ${ }^{5}$, DF Moore ${ }^{6}$ and GL Lu-Yao ${ }^{2,4,7,8}$ \\ ${ }^{1}$ State University of New York Downstate Medical Center, Brooklyn, NY, USA; ${ }^{2}$ Cancer Institute of New Jersey, New Brunswick, NJ, \\ USA; ${ }^{3}$ Division of Urology, Department of Surgery, University of Medicine and Dentistry of New Jersey, Robert Wood Johnson \\ Medical School, New Brunswick, NJ, USA; ${ }^{4}$ The Dean and Betty Gallo Prostate Cancer Center, New Brunswick, NJ, USA; \\ ${ }^{5}$ Department of Epidemiology and Biostatistics, The School of Public Health, Drexel University, Philadelphia, PA, USA; \\ ${ }^{6}$ Department of Biostatistics, The School of Public Health, University of Medicine and Dentistry in New Jersey, Piscataway, NJ, \\ USA; ${ }^{7}$ Department of Medicine, University of Medicine and Dentistry of New Jersey, Robert Wood Johnson Medical School, \\ New Brunswick, NJ, USA and ${ }^{8}$ Department of Epidemiology, The School of Public Health, University of Medicine and Dentistry in \\ New Jersey, Piscataway, NJ, USA
}

\begin{abstract}
The aim of this study was to assess the treatment patterns and 3-12-month complication rates associated with receiving prostate cryotherapy in a population-based study. Men $>65$ years diagnosed with incident localized prostate cancer in Surveillance Epidemiology End Results (SEER)-Medicare-linked database from 2004 to 2005 were identified. A total of 21344 men were included in the study, of which 380 were treated initially with cryotherapy. Recipients of cryotherapy versus aggressive forms of prostate therapy (ie, radical prostatectomy or radiation therapy) were more likely to be older, have one co-morbidity, low income, live in the South and be diagnosed with indolent cancer. Complication rates increased from 3 to 12 months following cryotherapy. By the twelth month, the rates for urinary incontinence, lower urinary tract obstruction, erectile dysfunction and bowel bleeding reached 9.8, 28.7, 20.1 and 3.3\%, respectively. Diagnoses of hydronephrosis, urinary fistula or bowel fistula were not evident. The rates of corrective invasive procedures for lower urinary tract obstruction and erectile dysfunction were both $<2.9 \%$ by the twelth month. Overall, complications post-cryotherapy were modest; however, diagnoses for lower urinary tract obstruction and erectile dysfunction were common.

Prostate Cancer and Prostatic Diseases (2011) 14, 313-319; doi:10.1038/pcan.2011.17; published online 26 April 2011
\end{abstract}

Keywords: cryotherapy; Medicare; prostatic neoplasms; Surveillance Epidemiology and End Results Program

\section{Introduction}

As the introduction of PSA screening, an increasing number of men are being diagnosed with low-grade, low-stage and small-volume cancers that are potentially biologically indolent. Consequently, choosing whether and how to treat these tumors remains challenging. Men newly diagnosed with low-risk prostate cancer are frequently treated with standard therapies (ie, radical prostatectomy, external beam radiation therapy, brachytherapy, androgen deprivation therapy (ADT) or conservative management), ${ }^{1}$ which are associated with high overall, cancer-specific and biochemical-recurrence free survival. However, radical prostatectomy, radiation therapy and ADT are accompanied by side effects

Correspondence: Dr GL Lu-Yao, Medical Oncology, The Cancer Institute of New Jersey, 195 Little Albany Street, Room 5534; New Brunswick, NJ, USA.

E-mail: luyaogr@umdnj.edu

Received 16 December 2010; revised 11 March 2011; accepted 12

March 2011; published online 26 April 2011 (eg, bladder and bowel dysfunction) that may impact negatively on health-related quality of life. Conversely, conservative management may induce anxiety and elevate stress levels. ${ }^{2}$ As such, renewed interest has emerged in using minimally invasive approaches, such as cryotherapy, to treat men diagnosed with clinically, localized prostate cancer.

Cryotherapy has become more widespread in practice because of a better understanding of cryobiology, ${ }^{3}$ introduction of third-generation cryoprobes and improvements in biopsy and imaging techniques, which have enhanced the ability to map the foci and location of tumors within the prostate and subsequently reduce morbidity while improving effectiveness. ${ }^{3-5}$

Although cryotherapy has been identified as a potential treatment option for men with clinically organ-confined disease by the American Urological Association, ${ }^{3}$ there is no formal definition of cryotherapy eligible tumors and a lack of information regarding the actual recipients of cryotherapy. Moreover, morbidity associated with cryotherapy has been primarily reported from single hospital-based studies, typically in highly 
selected patients. $^{6-14}$ Thus, in a population-based study, we identify the risk profile of men with clinically localized prostate cancer initially treated with cryotherapy and characterize post treatment-related complications.

\section{Materials and methods}

Data for this study were obtained from the 16 tumor registries participating in the National Cancer Institute's Surveillance Epidemiology End Results (SEER) program database linked to Medicare administrative claims. The SEER program monitors $\sim 26 \%$ of the United States population and has complete ascertainment in $98 \%$ of cases. ${ }^{15}$ Our study cohort consisted of men $\geqslant 66$ years diagnosed with incident, localized prostate cancer (ICD-O-3 site code C619) while enrolled in Medicare between 2004 and 2005. All patients were initially treated with cryotherapy, a form of aggressive standard therapy (ie, radical prostatectomy or radiation therapy) or nonaggressive standard therapy (ADT or conservative management) within 1 year of being diagnosed with prostate cancer. Men with advanced prostate cancer (T3 or T4) $(n=2519)$ or previous cancers $(n=4896)$ were excluded. Additional exclusion criteria included patients whose diagnosis of prostate cancer was obtained from autopsy or death certificate $(n=745)$, or tumor pathology not consistent with adenocarcinoma $(n=2167)$. Given that TURP increases the risk of urinary complications, men with a history of TURP $(n=32)$ or those who underwent TURP in combination with cryotherapy $(n=191)$ were excluded. ${ }^{16}$ Men with unknown Gleason score $(n=1120)$, PSA level $(n=4589)$, clinical stage $(n=1249)$ or covariates $(n=52)$ were also excluded. The final study cohort consisted of 21344 men newly diagnosed with localized prostate cancer.

\section{Treatment}

Cryotherapy and standard therapies were administered within 1 year following initial diagnosis of prostate cancer. Cryotherapy was identified from Medicare inpatient and outpatient claims using International Classification of Diseases, ninth revision, Clinical Modification (ICD-9-CM) procedure code 60.62, Current Procedural Terminology (CPT) code 55873, Health Care Financing Administration Common Procedure Coding System (HCPCS) codes G0160 and G0161 and SEER data. Standard forms of therapy were identified from Medicare-billing codes and SEER data.

\section{Complications}

ICD-9/CPT/HCPCS codes and Medicare claims data were used to ascertain the prevalence of diagnoses and invasive procedures reported for urinary, bowel and sexual function-related complications occurring 3, 6 and 12 months after cryotherapy. Patients with a Medicare claim of urinary, rectal or erectile dysfunction diagnoses or procedural-related complications before cryotherapy were excluded in order to identify the prevalence of posttreatment complications, which included lower urinary tract obstruction, erectile dysfunction, urinary incontinence, bowel bleeding, hydronephrosis, urinary fistula and bowel fistula. The medical codes for diagnoses and procedures for the aforementioned complications are provided in Appendix A.

\section{Covariates}

Demographic variables included age, race, marital status, income, geographic region, PSA, Gleason score, clinical stage, cancer-recurrence risk level and Charlson Comorbidity. Charlson co-morbidity score was derived from Medicare claims during the year before prostate cancer diagnosis by using a validated algorithm. ${ }^{17}$ Risk level, a measure of disease progression and PSA failure, was defined based on the risk model defined by the National Comprehensive Cancer Network. ${ }^{17}$ Low risk included clinical stage $\leqslant \mathrm{T} 2 \mathrm{a}$, PSA level $\leqslant 10 \mathrm{ng} \mathrm{ml}^{-1}$, Gleason score $\leqslant 6$; intermediate risk included clinical stage T2b-T2c, PSA $>10$ and $\leqslant 20 \mathrm{ng} \mathrm{ml}$, Gleason score $=7$; and high risk included PSA $>20 \mathrm{ng} \mathrm{ml}^{-1}$ and Gleason score $\geqslant 8$. $^{18}$

\section{Statistical analysis}

Multivariate logistic regression was used to estimate odds ratios and 95\% confidence intervals (CI) for the association between patient and tumor characteristics, and the selection of cryotherapy as opposed to aggressive or non-aggressive standard forms of therapy. Rates of urinary, bowel and sexual function-related diagnoses and corrective invasive procedures occurring 3, 6 and 12 months following cryotherapy are presented. All analyses were carried out using SAS statistical software (version 9.1, SAS Institute, Cary, NC, USA). The study was approved by the University of Medicine and Dentistry of New Jersey Institutional Review Board.

\section{Results}

A total of 380 patients (1.8\%) underwent cryotherapy as initial treatment for localized prostate cancer and had at least 1 year of follow-up after cryotherapy (Table 1). The majority of participants treated with cryotherapy, radical prostatectomy or radiation therapy were 66-74 years, $61.3 \%, 92.2$ and $62.6 \%$, respectively, whereas the majority of men given ADT or conservative management were $\geqslant 75$ years, 68.8 and $54.4 \%$, respectively. Most men treated with cryotherapy were diagnosed as having intermediate-risk disease $(50 \%)$, followed by low-risk $(33.7 \%)$ and high-risk $(16.1 \%)$ disease. Of cryotherapy patients, $70.5 \%$ had no co-morbidities, $22.1 \%$ had one comorbidity and $7.4 \%$ had at least two co-morbidities.

In multivariate analyses, age, marital status, income, geographic region, Gleason score and Charlson comorbidity score were significantly related to the selection of cryotherapy over aggressive therapies as initial treatment (Table 2). For instance, men $\geqslant 75$ years were 1.58 (95\% CI: 1.27, 1.95) times as likely to have cryotherapy than men 66-74 years. Income was inversely associated with the use of cryotherapy, such that men from low income were $1.46(95 \% \mathrm{CI}: 1.10,1.93)$ times as likely to receive cryotherapy than men from higher income. Gleason score was the only tumor-related characteristic that was associated with cryotherapy use.

High-risk patients were less likely to be treated with cryotherapy than low-risk patients (odds ratios $=0.70$; 
Table 1 Characteristics of patients treated with cryotherapy and standard forms of therapy for incident localized prostate cancer, SEERMedicare

\begin{tabular}{|c|c|c|c|c|c|}
\hline \multirow[t]{2}{*}{ Characteristics } & \multirow{2}{*}{$\begin{array}{l}\text { Cryotherapy } \\
(\mathrm{n}=380)\end{array}$} & \multicolumn{2}{|c|}{ Aggressive standard therapies } & \multicolumn{2}{|c|}{ Non-aggressive standard therapies } \\
\hline & & $\begin{array}{l}\text { Radical prostatectomy } \\
\qquad(\mathrm{n}=3960)\end{array}$ & $\begin{array}{l}\text { Radiation therapy } \\
\quad(\mathrm{n}=10757)\end{array}$ & $A D T(\mathrm{n}=3399)$ & $\begin{array}{l}\text { Conservative management } \\
\qquad(\mathrm{n}=2848)\end{array}$ \\
\hline \multicolumn{6}{|l|}{ Age (years) } \\
\hline $66-74$ & 61.3 & 92.2 & 62.6 & 31.2 & 45.6 \\
\hline $75+$ & 38.7 & 7.8 & 37.5 & 68.8 & 54.4 \\
\hline \multicolumn{6}{|l|}{ Race } \\
\hline White & 81.1 & 83.9 & 82.2 & 77.8 & 78.3 \\
\hline Black & 12.1 & 8.0 & 10.4 & 13.6 & 14.7 \\
\hline Other & 6.8 & 8.1 & 7.4 & 8.7 & 7.0 \\
\hline \multicolumn{6}{|l|}{ Marital status ${ }^{\mathrm{b}}$} \\
\hline Married & 66.8 & 81.8 & 75.0 & 56.4 & 57.3 \\
\hline Unmarried & 22.1 & 14.5 & 19.6 & 23.0 & 24.0 \\
\hline Unspecified & 11.1 & 3.7 & 5.3 & 20.7 & 18.8 \\
\hline Income \$ & $\$ 44315$ & $\$ 51582$ & $\$ 49526$ & $\$ 43257$ & $\$ 46088$ \\
\hline Median (IQR) & $(\$ 33090, \$ 57677)$ & $(\$ 39208, \$ 70418)$ & $(\$ 36371, \$ 66651)$ & $(\$ 31507, \$ 59650)$ & (\$33 294, 63501) \\
\hline \multicolumn{6}{|l|}{ Region } \\
\hline South & 32.4 & 12.4 & 17.4 & 20.5 & 18.1 \\
\hline North central & 7.9 & 12.6 & 12.6 & 11.8 & 10.0 \\
\hline Northeast & 10.0 & 10.4 & 26.5 & 17.8 & 15.2 \\
\hline West & 49.7 & 64.7 & 43.5 & 49.9 & 56.7 \\
\hline \multicolumn{6}{|l|}{$P S A\left(n g m l^{-1}\right)$} \\
\hline $0-2.5$ & 3.7 & 5.7 & 5.4 & 4.5 & 6.3 \\
\hline $2.6-\leqslant 4.0$ & 6.4 & 8.4 & 6.3 & 3.6 & 6.3 \\
\hline $4.1-\leqslant 10$ & 65.3 & 66.8 & 60.8 & 36.8 & 57.0 \\
\hline $10.1-19.9$ & 16.6 & 13.4 & 18.2 & 24.8 & 17.5 \\
\hline$\geqslant 20$ & 8.2 & 5.8 & 9.3 & 30.3 & 13.0 \\
\hline \multicolumn{6}{|l|}{ Gleason score } \\
\hline $2-6$ & 46.1 & 36.8 & 48.5 & 32.7 & 64.3 \\
\hline 7 & 44.2 & 49.8 & 36.7 & 37.3 & 24.8 \\
\hline $8-10$ & 9.7 & 13.4 & 14.9 & 30.0 & 10.9 \\
\hline \multicolumn{6}{|l|}{ Clinical stage } \\
\hline T1 & 50.5 & 55.3 & 57.1 & 44.2 & 52.7 \\
\hline $\mathrm{T} 2$ & 49.5 & 44.7 & 42.9 & 55.8 & 47.3 \\
\hline \multicolumn{6}{|l|}{ Risk ${ }^{c}$} \\
\hline Low & 33.7 & 28.1 & 34.6 & 17.7 & 46.6 \\
\hline Intermediate & 50.3 & 54.0 & 44.2 & 36.0 & 34.4 \\
\hline High & 16.1 & 18.0 & 21.3 & 46.3 & 19.0 \\
\hline \multicolumn{6}{|c|}{ Charlson co-morbidity } \\
\hline 0 & 70.5 & 84.0 & 73.8 & 66.1 & 72.6 \\
\hline 1 & 22.1 & 12.8 & 18.1 & 20.6 & 17.7 \\
\hline $2+$ & 7.4 & 3.2 & 8.1 & 13.3 & 9.8 \\
\hline
\end{tabular}

Abbreviations: ADT, androgen deprivation therapy; IQR, interquartile range; SEER, Surveillance Epidemiology End Results.

$\chi^{2}$ test was used to assess the independence of patient demographic and clinical characteristics across treatment groups. All $P$-values were $<0.001$.

${ }^{a}$ Radiation therapy includes external beam radiation therapy and brachytherapy.

${ }^{\mathrm{b}}$ Unmarried consists of men reported being separated, divorced or widowed.

${ }^{\mathrm{C}}$ Patients were categorized into three risk groups on the basis of clinical classification, PSA level and Gleason score: low-risk (T1-T2a and PSA level $<10$ ng $\mathrm{ml}^{-1}$ and Gleason score 2-6), intermediate-risk (T2b-T2c or $10 \leqslant$ PSA $\leqslant 20 \mathrm{ng} \mathrm{ml}^{-1}$ or Gleason score $=7$ ) and high-risk (PSA level $>20$ ng ml ${ }^{-1}$ or Gleason score $8-10$ ).

95\% CI: 0.51, 0.96) (Table 3). The use of cryotherapy did not vary between men with intermediate or low-risk disease (odds ratios $=1.00 ; 95 \%$ CI: $0.80,1.26$ ).

Within 3 months after undergoing cryotherapy, 23.7\% of men were diagnosed with or treated for lower urinary tract obstruction (Table 4). Erectile dysfunction, urinary incontinence and bowel bleeding were prevalent in 4.0, 3.8 and $<2.9 \%$ of men, respectively. By 6 months, the rate of erectile dysfunction was more than tripled and urinary incontinence doubled. At 12 months following cryotherapy, lower urinary tract obstruction, erectile dysfunction, urinary incontinence and bowel bleeding rose to 28.7, 20.1, 9.8 and $3.3 \%$ respectively. No man had a diagnosis or corrective invasive procedure within 12 months following cryotherapy for hydronephrosis, urinary fistula or bowel fistula. 
Table 2 Adjusted ${ }^{\text {a }}$ ORs (95\% CIs) for factors associated with the selection of cryotherapy instead of aggressive standard therapy ${ }^{b}$ in men diagnosed with incident localized prostate cancer, SEERMedicare

\begin{tabular}{|c|c|c|c|}
\hline Characteristics & $O R$ & $95 \% C I$ & P-value \\
\hline \multicolumn{4}{|l|}{ Age (years) } \\
\hline $\begin{array}{l}75+ \\
66-74\end{array}$ & 1.58 & $\begin{array}{l}(1.27,1.95) \\
\text { Referent }\end{array}$ & $<0.001$ \\
\hline \multicolumn{4}{|l|}{ Race } \\
\hline Black/Other & 0.99 & $(0.75,1.29)$ & 0.910 \\
\hline White & & Referent & \\
\hline \multicolumn{4}{|l|}{ Marital status ${ }^{c}$} \\
\hline Unmarried/Unspecified & 1.66 & $(1.33,2.07)$ & $<0.001$ \\
\hline Married & & Referent & \\
\hline \multicolumn{4}{|l|}{ Income } \\
\hline Lowest tertile & 1.46 & $(1.10,1.93)$ & 0.008 \\
\hline Middle tertile & 1.35 & $(1.03,1.77)$ & 0.031 \\
\hline Highest tertile & & Referent & \\
\hline \multicolumn{4}{|l|}{ Region } \\
\hline South & 1.81 & $(1.42,2.31)$ & $<0.001$ \\
\hline North central & 0.55 & $(0.37,0.81)$ & 0.003 \\
\hline Northeast & 0.45 & $(0.31,0.64)$ & $<0.001$ \\
\hline West & & Referent & \\
\hline \multicolumn{4}{|l|}{$P S A\left(n g m l^{-1}\right)$} \\
\hline $0.1-\leqslant 10$ & & Referent & \\
\hline $10.1-19.9$ & 0.92 & $(0.69,1.21)$ & 0.544 \\
\hline$\geqslant 20$ & 0.95 & $(0.65,1.40)$ & 0.805 \\
\hline \multicolumn{4}{|l|}{ Gleason score } \\
\hline $2-6$ & & Referent & \\
\hline 7 & 1.04 & $(0.84,1.29)$ & 0.732 \\
\hline $8-10$ & 0.60 & $(0.41,0.86)$ & 0.006 \\
\hline \multicolumn{4}{|l|}{ Clinical stage } \\
\hline $\mathrm{T} 2$ & 1.22 & $(0.99,1.50)$ & 0.059 \\
\hline $\mathrm{T} 1$ & & Referent & \\
\hline \multicolumn{4}{|l|}{ Charlson co-morbidity score } \\
\hline 0 & & Referent & \\
\hline 1 & 1.41 & $(1.10,1.81)$ & 0.008 \\
\hline $2+$ & 1.15 & $(0.77,1.71)$ & 0.498 \\
\hline
\end{tabular}

Abbreviations: CI, confidence interval; OR, odds ratio; SEER, Surveillance Epidemiology End Results.

${ }^{\mathrm{a}}$ Adjusted for patient and tumor characteristics included in the table.

${ }^{\mathrm{b}}$ Aggressive standard therapies include radical prostatectomy, external beam radiation therapy and brachytherapy.

${ }^{c}$ Unmarried consists of men reported being separated, divorced or widowed.

Of the patients diagnosed with urinary incontinence, no one had a corrective invasive procedure, $<11$ men had a procedure to alleviate lower urinary tract obstruction or to ameliorate erectile dysfunction.

\section{Discussion}

In this population-based study, we found that cryotherapy remains a novel strategy to treat men initially diagnosed with clinically localized prostate cancer. We observed that besides disease-risk level that several demographic characteristics are significantly associated with receiving cryotherapy. In addition, among men with no previous history of treatment-related complications,
Table 3 The adjusted $^{\mathrm{a}}$ association between the selection of cryotherapy instead of aggressive ${ }^{b}$ standard therapies in men diagnosed with incident localized prostate cancer, SEER-Medicare

\begin{tabular}{llll}
\hline NCCN criterion $^{c}$ & OR & $95 \%$ CI & P-value \\
\hline High & 0.70 & $(0.51,0.96)$ & 0.026 \\
Intermediate & 1.00 & $\begin{array}{l}(0.80,1.26) \\
\text { Referent }\end{array}$ & 0.986 \\
Low & & R & \\
\hline
\end{tabular}

Abbreviations: CI, confidence interval; NCCN, The National Comprehensive Cancer Network; OR, odds ratio; SEER, Surveillance Epidemiology End Results.

aAdjusted for age, race, marital status, income, region and Charlson co-morbidity score.

${ }^{\mathrm{b}}$ Aggressive standard therapies include radical prostatectomy, external beam radiation therapy and brachytherapy.

${ }^{c}$ Patients were categorized into three risk groups on the basis of clinical classification, PSA level and Gleason score: low-risk (T1-T2a and PSA level $<10 \mathrm{ng} \mathrm{ml}^{-1}$ and Gleason score 2-6), intermediate-risk (T2b-T2c or $10 \leqslant$ PSA $\leqslant 20 \mathrm{ng} \mathrm{ml}^{-1}$ or Gleason score $=7$ ) and high-risk (PSA level $>20 \mathrm{ng} \mathrm{ml}^{-1}$ or Gleason score 8-10).

the rates of urinary incontinence, hydronephrosis, bowel bleeding, urinary fistula and bowel fistula post treatment were minimal. However, the rates of lower urinary tract obstruction and erectile dysfunction are common, but there is little need for ancillary corrective, invasive procedures.

Although men with high-risk disease were significantly less likely to receive cryotherapy than men with low-risk disease, nearly one in five men administered cryotherapy had high-risk disease (16.1\%), indicating that in clinical practice cryotherapy is being used in patients with more aggressive cancers, (ie, men with PSA levels $>20 \mathrm{ng} \mathrm{ml}^{-1}$ or Gleason score 8-10). Albeit selection criteria for men undergoing prostate cryotherapy have yet to be definitively established, optimal candidates for this procedure generally include those with lower stage, lower-volume disease with PSA levels $<20 \mathrm{ng} \mathrm{ml}^{-1}$.

Interestingly, an inverse association between income and cryotherapy was observed. This may indicate that cryotherapy is becoming an attractive alternative for men with lesser means possibly in part because it is associated with shorter hospital stay, faster recovery time and is theoretically less costly than standard therapy. ${ }^{20}$ Our findings support past studies, which have demonstrated that men with lower socioeconomic status were less likely to receive aggressive therapy in comparison with their richer counterparts. ${ }^{21}$ For example, Cooperberg et al. recently reported that a greater percentage of men with an annual income of $<\$ 20000, \$ 20000-\$ 30000$ or $\$ 3000-\$ 50000$ were treated with cryotherapy than men with an annual income $\geqslant \$ 50000 .^{22}$

Of particular significance in our study, is the finding that the proportion of patients developing erectile dysfunction or urinary incontinence may increase over time, suggesting that the effects of cryotherapy may not only arise immediately after cryotherapy, but also remotely. For instance, from 6 to 12 months following treatment, the rates of erectile dysfunction increased from 13.2 to $20.1 \%$, and urinary incontinence rose from 7.9 to $9.8 \%$.

Complications occurring after cryotherapy have been widely studied in small single hospital-based studies. Reports of urinary incontinence ranged from 1.3 to $9.5 \%$, $7,9-12,14,23-25$ urinary strictures from 1.7 to $3.4 \%, 10,12,14$ lower urinary tract obstruction/retention 
Table 4 Combined diagnoses and procedural related complications reported 3, 6 and 12 months after cryotherapy in men diagnosed with incident localized prostate cancer and no previous history of treatment. related morbidity, SEER-Medicare

\begin{tabular}{|c|c|c|c|c|c|c|}
\hline \multirow[t]{2}{*}{ Complication } & \multicolumn{2}{|c|}{3 months } & \multicolumn{2}{|c|}{6 months } & \multicolumn{2}{|c|}{12 months } \\
\hline & $\mathrm{n}$ & $\%$ & $\mathrm{n}$ & $\%$ & $\mathrm{n}$ & $\%$ \\
\hline Lower urinary tract obstruction ${ }^{a}$ & 78 & 23.7 & 90 & 27.4 & 94 & 28.7 \\
\hline Erectile dysfunction ${ }^{\mathrm{b}}$ & 14 & 4 & 46 & 13.2 & 70 & 20.1 \\
\hline Urinary incontinence $^{c}$ & 14 & 3.8 & 29 & 7.9 & 36 & 9.8 \\
\hline Bowel bleeding $^{\mathrm{d}}$ & $<11$ & $<2.9$ & $<11$ & $<2.9$ & 12 & 3.3 \\
\hline Hydronephrosis ${ }^{\mathrm{e}}$ & 0 & 0 & 0 & 0 & 0 & 0 \\
\hline Urinary fistula $^{\mathrm{f}}$ & 0 & 0 & 0 & 0 & 0 & 0 \\
\hline Bowel fistula $^{g}$ & 0 & 0 & 0 & 0 & 0 & 0 \\
\hline
\end{tabular}

Abbreviation: SEER, Surveillance Epidemiology End Results.

a Lower urinary tract obstruction included medical claim of dilation, urethrotomy, urethroplasty, sphincterotomy, transurethral prostate resection/destruction, urethral stent or injection for strictureoccuring. In all, 328 men had no previous history of urinary obstruction before cryotherapy.

${ }^{\mathfrak{b}}$ Erectile Dysfunction included medical claim for penile prosthesis or intracavernosal. In all, 349 men had no previous history of erectile dysfunction before cryotherapy.

'Urinary incontinence included a medical claim of urethra sphincter injection, artificial sphincter or incontinence repair (sling, urethroplasty) occuring. In all, 368 men had no previous history of urinary incontinence before cryotherapy.

${ }^{\mathrm{d}}$ Bowel bleeding included hemorrhage or inflammation. In all, 359 men did not have bowel bleeding before cryotherapy.

${ }^{\mathrm{e}} \mathrm{Hydronephrosis}$ is distention of the renal pelvic and calices of the kidney with urine.

${ }^{\mathrm{f}}$ Bowel Fistula included medical claims of rectal repair, colostomy or ulcer.

'Urinary Fistula was defined as medical claims with repair of bowel-bladder fistula or closure of urethrostomy or urethrocutaneous fistula occurring.

from 13 to $23 \%,^{24,26-28}$ bowel bleeding was $2.0 \%{ }^{12}$ and erectile dysfunction from 47 to $94.9 \% .^{7,10,11,14}$ Consistently, cryotherapy was found to be associated with a low rate of fistulas $(<1 \%)$ several years after the procedure. ${ }^{7,10-14}$

In our cohort of men receiving prostate cryotherapy, no urinary or bowel fistulas or hydronephrosis were reported, and bowel bleeding was observed to be low at 12 months after cryotherapy. The 12-month rates of lower urinary tract obstruction and urinary incontinence in this study were greater than reported in previous studies. The higher complication rates found in this study may reflect differences in the definition of the complications, the use of population-based data as opposed to hospital-based data or publication bias. In particular, the higher rates of postoperative urinary incontinence may be indicative of the higher rates of mild to severe urinary symptoms in older men ${ }^{29,30}$ that often is underreported, ${ }^{30,31}$ and a larger prostate volume, ${ }^{32}$ which interferes with urinary incontinence. Thus, the older men in this study may have some degree of preexisting urinary dysfunction or larger prostate, which may augment their risk of urinary incontinence post cryotherapy. The rate of erectile dysfunction in this study was lower than previous estimates and may be attributed to our study population consisting of men 66 years of age or older. Older men may not be as concerned about reporting and treating erectile dysfunction as younger men. In addition, some cases of erectile dysfunction may not have been identified because we lacked validated instruments to assess erectile dysfunction such as the International Index of Erectile Function, ${ }^{33}$ the Quality of Erection Questionnaire $^{34}$ or the Sexual Health Inventory for Men. ${ }^{35}$ It is also feasible that the rate of erectile dysfunction may have been underestimated during the study period because some patients may have used devices or agents (eg, vacuum erection device, internal penile pump, phosphodiesterase type 5 inhibitors) to rectify their erectile dysfunction.

The postoperative complication rates may also vary across studies because of differences in tumor characteristics (eg, gland size), rates of complications precryotherapy (eg, impotency), duration of follow-up, definition of complications, inclusion of men with a history of TURP, use of previous treatments (eg, external beam radiation therapy) and the generation of the cryotherapy device(s).

An advantage of this study is that updated data pertaining to cryotherapy were used. Previous studies reported outcomes when cryotechnology and imaging were evolving. ${ }^{7,9-14,23}$ As thereafter, further technological advancements in the field have been achieved, such as the use of argon gas instead liquid nitrogen, which has enabled cryotherapy to be delivered in a more precise, safer and efficacious manner. ${ }^{3,36}$ Consequently, our findings provide valuable insight into the prevalence of morbidity associated with this treatment in a technologically more advanced era.

Certain limitations of our study warrant mention. Although our findings likely reflect clinical practice in the United States because the SEER database covers 26\% of the United States population, we were unable to explore the influence of other pertinent risk factors, such as gland volume and configurations. Additionally, given that the data for this study were extracted from administrative claims data, we were unable to evaluate erectile dysfunction and urinary complications using validated instruments of quality of life. ${ }^{33-35}$ Thus, the rates of these complications may be underestimated. Further, because of the inherent limitations of using administrative claims data, we were unable to decipher the generation of the cryotherapy devices that were performed on patients. However, given that the procedures occurred within a narrow window of time from 2004 to 2005, variation in the generation of the cryotherapy devices used was most likely minimized.

The results from this study may not be generalizable to younger men because Medicare consists of men 65 years and older. We also could not distinguish between wholegland cryotherapy and focal cryotherapy, as current procedural codes do not exist to allow for this differentiation. Finally, the use of administrative claims to estimate treatment-related complications may result in an underestimation of the true complication prevalence.

In summary, our findings provide an estimate of contemporary post-treatment complications associated with cryotherapy. The results from this study suggest that among men diagnosed with localized prostate cancer that morbidity post cryotherapy is modest; lower urinary tract obstruction and erectile dysfunction remain common following cryotherapy; complications can manifest even 1 year after treatment; and a small proportion of men may require invasive corrective procedures to address these complications. Patients should be fully informed of the complications presented herein, as well as the lack of well-controlled or randomized studies supporting its efficacy. 


\section{Conflict of interest}

The authors declare no conflict of interest.

\section{Acknowledgements}

We acknowledge the efforts of the Applied Research Branch, Division of Cancer Prevention and Population Science, NCI; the Office of Information Services and the Office of Strategic Planning, CMS; Information Management Services (IMS), Inc.; and the Surveillance, Epidemiology and End Results (SEER) Program tumor registries in the creation of the SEER-Medicare database. The performance and design of this study was reviewed and approved by both the National Cancer Institute (NCI) and Center for Medicare and Medicaid Services (CMS). This study was supported by an award from the Robert Wood Johnson Foundation grant \#60624 and by the biometric Shared Resource(s) of The Cancer Institute of New Jersey (P30CA072720).

\section{Disclaimer}

This study utilizes the linked SEER-Medicare database. The interpretation and reporting of these data are the sole responsibility of the authors. The content of the information does not necessarily reflect the position or the policy of the Government or the employers, and no official endorsement should be inferred.

\section{References}

1 Cooperberg MR, Lubeck DP, Meng MV, Mehta SS, Carroll PR. The changing face of low-risk prostate cancer: trends in clinical presentation and primary management. J Clin Oncol 2004; 22: 2141-2149.

2 Dale W, Bilir P, Han M, Meltzer D. The role of anxiety in prostate carcinoma: a structured review of the literature. Cancer 2005; 104 467-478.

3 Babaian RJ, Donnelly B, Bahn D, Baust JG, Dineen M, Ellis D et al. Best practice statement on cryosurgery for the treatment of localized prostate cancer. J Urol 2008; 180: 1993-2004.

4 Saliken JC, Donnelly BJ, Rewcastle JC. The evolution and state of modern technology for prostate cryosurgery. Urology 2002; 60: 26-33.

5 Sartor AO, Hricak H, Wheeler TM, Coleman J, Penson DF, Carroll PR et al. Evaluating localized prostate cancer and identifying candidates for focal therapy. Urology 2008; 72: S12-S24.

6 Malcolm JB, Fabrizio MD, Barone BB, Given RS, Lance DF, Lynch JW et al. Quality of life after open or robotic prostatectomy, cryoablation or brachytherapy for localized prostate cancer. J Urol 2010; 183: 1822-1828.

7 Coogan CL, McKiel CF. Percutaneous cryoablation of the prostate: preliminary results after 95 procedures. J Urol 1995; 154: 1813-1817.

8 Ellis DS, Manny Jr TB, Rewcastle JC. Focal cryosurgery followed by penile rehabilitation as primary treatment for localized prostate cancer: initial results. Urology 2007; 70: 9-15.

9 Donnelly BJ, Saliken JC, Ernst DS, Ali-Ridha N, Brasher PM, Robinson JW et al. Prospective trial of cryosurgical ablation of the prostate: five-year results. Urology 2002; 60: 645-649.

10 Aus G, Pileblad E, Hugosson J. Cryosurgical ablation of the prostate: 5-year follow-up of a prospective study. Eur Urol 2002, 42: $133-138$
11 Bahn DK, Lee F, Badalament R, Kumar A, Greski J, Chernick M. Targeted cryoablation of the prostate: 7-year outcomes in the primary treatment of prostate cancer. Urology 2002; 60: 3-11.

12 Cohen JK. Cryosurgical ablation of the prostate: two-year prostate-specific antigen and biopsy results. Urology 1996; 48: 178-180.

13 Prepelica KL, Okeke Z, Murphy A, Katz AE. Cryosurgical ablation of the prostate: high risk patient outcomes. Cancer 2005; 103: $1625-1630$.

14 Long JP, Fallick ML, LaRock DR, Rand W. Preliminary outcomes following cryosurgical ablation of the prostate in patients with clinically localized prostate carcinoma. J Urol 1998; 159: 477-484.

15 Warren JL, Klabunde CN, Schrag D, Bach PB, Riley GF. Overview of the SEER-Medicare data: content, research applications, and generalizability to the United States elderly population. Med Care 2002; 40: IV-3-IV-18.

16 Shinohara K, Connolly JA, Presti Jr JC, Carroll PR. Cryosurgical treatment of localized prostate cancer (stages T1 to T4): preliminary results. J Urol 199; 15: 115-121.

17 Klabunde CN, Potosky AL, Legler JM, Warren JL. Development of a comorbidity index using physician claims data. J Clin Epidemiol. Dec 2000; 53: 1258-1267.

18 National Comprehensive Cancer Network 2010 Available at: http:/ /www.nccn.org. Accessed (March 15, 2010).

19 Finley DS, Pouliot F, Miller DC, Belldegrun AS. Primary and salvage cryotherapy for prostate cancer. Urol Clin North Am 2010; 37: 67-82.

20 Ritch CR, Katz AE. Prostate cryotherapy: current status. Curr Opin Urol 2009; 19: 177-181.

21 Kane CJ, Lubeck DP, Knight SJ, Spitalny M, Downs TM, Grossfeld GD et al. Impact of patient educational level on treatment for patients with prostate cancer: data from CaPSURE. Urology 2003; 62: 1035-1039.

22 Cooperberg MR, Broering JM, Carroll PR. Time trends and local variation in primary treatment of localized prostate cancer. J Clin Oncol 2010; 28: 1117-1123.

23 Wong WS, Chinn DO, Chinn M, Chinn J, Tom WL. Cryosurgery as a treatment for prostate carcinoma: results and complications. Cancer 1997; 9: 963-974.

24 Long JP, Bahn D, Lee F, Shinohara K, Chinn Do, Macaluso Jr JN. Five-year retrospective, multi-institutional pooled analysis of cancer-related outcomes after cryosurgical ablation of the prostate. Urology 2001; 57: 518-523.

25 Kimura M, Mouraviev V, Tsivian M, Moreira DM, Mayes JM, Polascik TJ. Analysis of urinary function using validated instruments and uroflowmetry after primary and salvage prostate cryoablation. Urology 2010; 76: 1258-1265.

26 Long JP. Is there a role for cryoablation of the prostate in the management of localized prostate carcinoma? Hematol Oncol Clin North Am 1996; 10: 675-690.

27 Shinohara K, Rhee B, Presti Jr JC, Carroll PR. Cryosurgical ablation of prostate cancer: patterns of cancer recurrence. J Urol 1997; 158: 2206-2210.

28 Wake RW, Hollabaugh Jr RS, Bond KH. Cryosurgical ablation of the prostate for localized adenocarcinoma: a preliminary experience. J Urol 1996; 155: 1663-1666.

29 Markland AD, Goode PS, Redden DT. Prevalence of urinary incontinence in men: results from the national health and nutrition examination survey. J Urol 2010; 84: 1022-1027.

30 Diokno AC, Estanol MVC, Ibrahim A, Balasubramaniam M. Prevlance of urinary incontinence in community dwelling men: a cross sectional nationwide epidemiological survey. Int Urol Nephrol 2007; 39: 129-136.

31 Dugan E, Roberts CP, Cohens SJ, , Preisser JS, , Davis CC, Bland DR et al. Why older community-dwelling adults do not discuss urinary incontinence with their primary care physicians. J AM Geriatr 2001; 49: 462-465.

32 Roehrborn CG, Boyle P, Gould AL, Waldstreicher J. Serum prostate-specific antigen as a predictor of prostate volume in men with benign prostatic hyperplasia. Urology 1999; 53: 581-589. 
33 Rosen RC, Riley A, Wagner G, Osterloh IH, Kirkpatrick J, Mishra A. The international index of erectile function (IIEF): A multidimensional scale for assessment of erectile dysfunction. Urology 1997; 49: 822-830.

34 Rhoden EL, Telöken C, Sogari PR, Vargas Souto CA. The use of the simplified International Index of Erectile Function (IIEF-5) as a diagnostic tool to study the prevalence of erectile dysfunction. Int J Impotence Res 2002; 14: 242-250.

35 Wei J, Dunn R, Litwin M, Sandler H, Sanda M. Development and Validation of the Expanded Prostate Cancer Index Composite (EPIC) for Comprehensive Assessment of Health-Related Quality of Life in Men with Prostate Cancer. Urology 2000; 56: 899-905.

36 De La Taille A, Benson MC, Bagiella E, , Burchardt M, , Shabsigh A, Olsson CA et al. Cryoablation for clinically localized prostate cancer using an argon-based system: complication rates and biochemical recurrence. BJU Int 2000; 85: 281-286.

Appendix A Definitions of complications following cryotherapy

\begin{tabular}{|c|c|c|c|}
\hline \multirow[t]{3}{*}{ Complications } & \multicolumn{3}{|c|}{ Medical codes } \\
\hline & \multirow{2}{*}{$\begin{array}{l}\text { Diagnoses } \\
\text { ICD-9-CM }\end{array}$} & \multicolumn{2}{|r|}{ Procedures } \\
\hline & & $I C D-9-C M$ & CPT/HCPCS \\
\hline \multicolumn{4}{|l|}{ Erectile } \\
\hline Impotence, dysfunction & 607.84 & & \\
\hline Penile prosthesis & & $64.94,64.95,64.96,64.97$ & $\begin{array}{l}54400,54401,54402,54405,54407,4408,54409, \\
54410,54411,54415,54416,54417, \text { C } 1007, \text { C } 1813 \\
\text { C2622, C } 3500, \text { C } 8514, \text { C } 8516, \text { C } 8534, \text { L7900 }\end{array}$ \\
\hline Intracavernosal injection & & & $54231,54235, \mathrm{~J} 0270, \mathrm{~J} 0275, \mathrm{~J} 2440, \mathrm{~J} 2760$ \\
\hline \multicolumn{4}{|l|}{ Lower urinary tract obstruction } \\
\hline Stricture, obstruction, retention & $\begin{array}{c}596.0,598 x \\
599.6,788.2 x\end{array}$ & & \\
\hline $\begin{array}{l}\text { Dilation, urethrotomy, } \\
\text { urethroplasty, sphincterotomy }\end{array}$ & & $\begin{array}{c}57.85,57.91,57.92,58.0,58.1,58.3 x \\
58.44,58.46,58.47,58.5,58.6,58.99 \\
60.95\end{array}$ & $\begin{array}{c}52275,52276,52281,52510,53010,53400,53405 \\
53410,53415,53420,53425,53600,53601 \\
53605,53620,53621\end{array}$ \\
\hline $\begin{array}{l}\text { Transurethral prostate } \\
\text { resection/destruction }\end{array}$ & & $60.2 x$ & $52601,52612,52614,52620,52630,53850,53852$ \\
\hline Urethral stent & & & 2282 \\
\hline Injection for stricture & & & 52283 \\
\hline \multicolumn{4}{|l|}{ Urinary incontinence } \\
\hline $\begin{array}{l}\text { Incontinence, sphincter, } \\
\text { deficiency }\end{array}$ & $788.3 x, 599.82$ & & \\
\hline Urethra, sphincter injection & & 59.72 & 51715 \\
\hline Artificial sphincter & & 58.93 & 53445,53447 \\
\hline $\begin{array}{l}\text { Incontinence repair (sling, } \\
\text { urethroplasty) }\end{array}$ & & $59.3,59.4,59.5,59.6,59.71,59.79$ & $53440,51840,51841,53442,53443$ \\
\hline Urinary fistula & $\begin{array}{l}596.1,596.2 \\
599.1\end{array}$ & $57.83,57.84,58.43$ & $44660,44661,53520$ \\
\hline Urethral fistula & 5991 & & \\
\hline Intestinovesical fistula & 5961 & & \\
\hline Vesical fistula NEC & 5962 & & \\
\hline $\begin{array}{l}\text { Repair of a bowel-bladder } \\
\text { fistula or closure of } \\
\text { urethrostomy }\end{array}$ & & $5783,5784,5843$ & $44660,44661,53520$ \\
\hline \multicolumn{4}{|l|}{ Bowel fistula } \\
\hline Fistula, ulcer & $569.41,569.81$ & $48.73,48.93$ & $45800,45805,45820,45825$ \\
\hline Rectal repair, colostomy & & $46.1 x, 48.31,48.32,48.33$ & 45562,45563 \\
\hline \multicolumn{4}{|l|}{ Hydronephrosis } \\
\hline $\begin{array}{l}\text { Distention of the renal pelvic } \\
\text { and calices of the kidney with } \\
\text { urine }\end{array}$ & 591 & & \\
\hline \multicolumn{4}{|l|}{ Bowel bleeding } \\
\hline Hemorrhage, inflammation & $\begin{array}{l}558.1,569.3 \\
578.9\end{array}$ & & \\
\hline
\end{tabular}

Abbreviations: CPT, current procedural terminology; HCPCS, Health Care Financing Administration Common Procedure Coding System; ICD-9-CM, International Classification of Diseases, 9th revision, Clinical Modification.

Medical codes regarding diagnoses and corrective invasive procedures for complications occurring after cryotherapy as initial treatment for prostate cancer. 